\title{
A strategy to find novel candidate anti-Alzheimer's disease drugs by constructing interaction networks between drug targets and natural compounds in medical plants
}

\author{
Bi-Wen Chen ${ }^{1,2}$, Wen-Xing Li ${ }^{2,3}$ ， Guang-Hui Wang ${ }^{1}$, Gong-Hua Li ${ }^{2,3}$ ， Jia-Qian Liu ${ }^{4}$, Jun-Juan Zheng ${ }^{2,3}$,

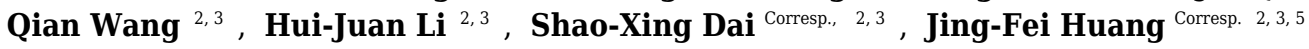 \\ ${ }^{1}$ College of Pharmaceutical Sciences, Soochow University, Suzhou, Jiangsu, China \\ 2 State Key Laboratory of Genetic Resources and Evolution, Kunming Institute of Zoology, Chinese Academy of Sciences, Kunming, Yunnan, China \\ 3 Kunming College of Life Science, University of Chinese Academy of Sciences, Kunming, Yunnan, China \\ 4 School of Life Sciences, Zhengzhou University, Zhengzhou, Henan, China \\ 5 KIZ-SU Joint Laboratory of Animal Models and Drug Development, College of Pharmaceutical Sciences, Soochow University, Kunming, Yunnan, China \\ Corresponding Authors: Shao-Xing Dai, Jing-Fei Huang \\ Email address: daishaoxing@mail.kiz.ac.cn, huangjf@mail.kiz.ac.cn
}

Background Alzheimer' disease (AD) is an ultimately fatal degenerative brain disorder that has an increasingly large burden on health and social care systems. There are only five drugs for AD on the market, and no new effective medicines have been discovered for many years. Chinese medicinal plants have been used to treat diseases for thousands of years, and screening herbal remedies is a way to develop new drugs.

Methods We used molecular docking to screen 30,438 compounds from Traditional Chinese Medicine (TCM) against a comprehensive list of AD target proteins. TCM compounds in the top $0.5 \%$ of binding affinity scores for each target protein were selected as our research objects. Structural similarities between existing drugs from DrugBank database and selected TCM compounds as well as the druggability of our candidate compounds were studied. Finally, we searched the CNKI database to obtain studies on anti-AD Chinese plants from 2007 to 2017, and only clinical studies were included.

Results A total of 1476 compounds (top $0.5 \%$ ) were selected as drug candidates. Most of these compounds are abundantly found in plants used for treating AD in China, especially the plants from two genera Panax and Morus. We classified the compounds by single target and multiple targets and analyzed the interactions between target proteins and compounds. Analysis of structural similarity revealed that 17 candidate anti-AD compounds were structurally identical to 14 existing approved drugs. Most of them have been reported to have a positive effect in AD. After filtering for compound druggability, we identified 11 anti-AD compounds with favorable properties, 7 of which are found in antiAD Chinese plants. Of 11 anti-AD compounds, 4 compounds 5862, 5863, 5868, 5869 have antiinflammatory activity. The compound 28814 mainly has immunoregulatory activity. The other 6 compounds have not yet been reported for any biology activity at present.

Discussion Natural compounds from TCM provide a broad prospect for the screening of anti-AD drugs. In this work, we established networks to systematically study the connections among natural compounds, approved drugs, TCM plants and AD target proteins with the goal of identifying promising drug candidates. We hope that our study will facilitate in-depth research for the treatment of AD in Chinese medicine. 
1 A strategy to find novel candidate anti-Alzheimer's disease drugs by constructing

2 interaction networks between drug targets and natural compounds in medical plants

3

4 Bi-Wen Chen ${ }^{\mathrm{a}, \mathrm{b}, 1}$, Wen-Xing Li ${ }^{\mathrm{b}, \mathrm{c}, 1}$, Guang-Hui Wanga ${ }^{\mathrm{a}}$, Gong-Hua Li ${ }^{\mathrm{b}, \mathrm{c}}$, Jia-Qian Liu ${ }^{\mathrm{d}}$, Jun-Juan

5 Zheng ${ }^{b, c}$, Qian Wang ${ }^{b, c}$, Hui-Juan Li ${ }^{b, c}$, Shao-Xing Dai ${ }^{b, c, *}$ and Jing-Fei Huang,c,e,*

6 aCollege of Pharmaceutical Sciences, Soochow University, Suzhou 215006, Jiangsu, China

7 bState Key Laboratory of Genetic Resources and Evolution, Kunming Institute of Zoology,

8 Chinese Academy of Sciences, Kunming 650223, Yunnan, China

9 'Kunming College of Life Science, University of Chinese Academy of Sciences, Kunming

10 650204, Yunnan, China

11 dSchool of Life Sciences, Zhengzhou University, Zhengzhou, Henan 450001, China

12 eKIZ-SU Joint Laboratory of Animal Models and Drug Development, College of Pharmaceutical

13 Sciences, Soochow University, Kunming 650223, Yunnan, China

$15{ }^{1}$ These authors contributed equally to this work.

$16{ }^{*}$ Correspondence authors:

17 Shao-Xing Dai (daishaoxing@mail.kiz.ac.cn)

18 Jing-Fei Huang (huangjf@mail.kiz.ac.cn)

19 Tel: +86087165195183 


\section{ABSTRACT \\ Background}

Alzheimer' disease (AD) is an ultimately fatal degenerative brain disorder that has an increasingly large burden on health and social care systems. There are only five drugs for AD on the market, and no new effective medicines have been discovered for many years. Chinese medicinal plants have been used to treat diseases for thousands of years, and screening herbal remedies is a way to develop new drugs.

\section{Methods}

We used molecular docking to screen 30,438 compounds from Traditional Chinese Medicine (TCM) against a comprehensive list of AD target proteins. TCM compounds in the top $0.5 \%$ of binding affinity scores for each target protein were selected as our research objects. Structural similarities between existing drugs from DrugBank database and selected TCM compounds as well as the druggability of our candidate compounds were studied. Finally, we searched the CNKI database to obtain studies on anti-AD Chinese plants from 2007 to 2017, and only clinical studies were included.

\section{Results}

A total of 1476 compounds (top 0.5\%) were selected as drug candidates. Most of these compounds are abundantly found in plants used for treating AD in China, especially the plants from two genera Panax and Morus. We classified the compounds by single target and multiple targets and analyzed the interactions between target proteins and compounds. Analysis of structural similarity revealed that 17 candidate anti-AD compounds were structurally identical to 14 existing approved drugs. Most of them have been reported to have a positive effect in AD. After filtering for compound druggability, we identified 11 anti-AD compounds with favorable properties, 7 of which are found in anti-AD Chinese plants. Of 11 anti-AD compounds, 4 compounds 5862, 5863, 5868, 5869 have anti-inflammatory activity. The compound 28814 mainly has immunoregulatory activity. The other 6 compounds have not yet been reported for any biology activity at present. 


\section{Discussion}

48 Natural compounds from TCM provide a broad prospect for the screening of anti-AD drugs.

49 In this work, we established networks to systematically study the connections among natural 50 compounds, approved drugs, TCM plants and AD target proteins with the goal of identifying 51 promising drug candidates. We hope that our study will facilitate in-depth research for the 52 treatment of AD in Chinese medicine. 


\section{INTRODUCTION}

Alzheimer's disease (AD), a progressive and ultimately fatal degenerative brain disorder, is thought to be one of the main causes of dementia in senior citizens (Fan \& Chiu 2014; Song et al. 2015) (Fan \& Chiu 2014; Song et al. 2015). The psychiatric symptoms observed in AD patients, include irritability, changes in mood or personality, paranoid delusions and hallucinations (Coyle et al. 1983). The pathological features of AD include senile plaques and neurofibrillary degeneration (Dickson 1997). Degeneration, caused by neurofibrillary tangles (intracellular fibrous aggregations of tau protein), mainly occurs in brain regions involved in learning, memory, and emotional behaviors, such as the hippocampus, basal forebrain, entorhinal cortex and amygdala (Mattson 2004). The various hypotheses regarding AD pathogenesis suggest the involvement of many pathways and target proteins, such as the amyloid (Goedert \& Spillantini 2006), cholinergic (Craig et al. 2011), oxidative stress (Pratico 2008), glutamatergic (Bezprozvanny \& Mattson 2008), inflammatory (Trepanier \& Milgram 2010) and metal hypotheses (Bonda et al. 2011). However, the causes of AD remain unclear due to the complexity of this multifactorial disease (Armstrong 2013). To date, five symptom-relieving drugs are available to AD patients in a clinical setting, including four cholinesterase inhibitors and one N-methyl-D-aspartate (NMDA) -receptor antagonist. However, there is currently no method for reversing or curing AD (Cummings et al. 2014; Peng et al. 2016), and Tacrine has been discontinued in the United States market. Thus, the discovery of new drugs for treating AD patients remains a challenge.

Traditional Chinese Medicines (TCMs) have been used in therapy and for treating various diseases for several thousand years of Chinese history, and some natural ingredients in TCMs have been successfully developed into drug, such as artemisinin. Screening natural ingredients or compounds from herbal remedies and TCMs may be an effective way to develop new drugs (Normile 2003; Sanderson 2011; Sucher 2013). For example, interactions between some ingredients from anti-AD herbs and corresponding anti-AD target proteins (Sun et al. 2013) as well as between 12 ginger components and 13 anti-AD target proteins have been reported (Azam 
81

82

83

84

85

86

87

et al. 2014). Many AD target proteins have previously been validated, including AchE (Yiannopoulou \& Papageorgiou 2013), BchE (Darvesh 2016; Mushtaq et al. 2014), RAGE (Cai et al. 2016; Deane 2012), TNF-alpha (Leszek et al. 2016; Wyss-Coray \& Rogers 2012), PLA2 (Gentile et al. 2012; Lee et al. 2011) and others. These proteins are involved in a variety of ADassociated pathways. Because we wanted to study a comprehensive range of AD target proteins, we selected 30 target proteins with protein crystal structures (including ligand present in the crystal structure) from all of the validated AD therapeutic target proteins provided by Thomson Reuters Integrity database as our research objects. To explore the interactions between the 30 validated $\mathrm{AD}$ therapeutic target proteins, which represent a variety of hypotheses regarding $\mathrm{AD}$ pathogenesis, and compounds in TCM plants, we established interaction networks among the target proteins, compounds, approved drugs and TCMs. Finally, we identified 11 structurally novel candidate anti-AD compounds with favorable druggability properties, 7 of which are found in anti-AD Chinese plants. The 11 compounds identified in this study may be valuable in future anti-AD drug development, though further experiments are needed to prove their usefulness as drugs. The results suggest that the strategy of interaction network-based drug discovery may be very helpful for drug development.

\section{MATERIALS AND METHODS}

\section{Data collection and preprocessing}

More than 60,000 natural compounds from 8,529 different plants were from the TCM Database@Taiwan (http://tcm.cmu.edu.tw/). This web-based database is the most comprehensive non-commercial database of $\operatorname{TCM}($ Chen 2011). We obtained the 3D structures of the compounds from the database as mol2 files and converted them to the pdbqt format and SMILES string using Open Babel toolbox v2.3.1(O'Boyle et al. 2011).

The validated therapeutic AD target proteins and pathways were provided by Thomson Reuters Integrity database (https://integrity.thomson-pharma.com/integrity/). Studies on the target proteins were obtained using Pubmed and PMC (https://www.ncbi.nlm.nih.gov/pubmed). The target proteins structures were obtained from the Protein Data Bank (PDB) database 
108

109

110

111

112

113

114

115

116

117

118

119

120

121

122

123

124

125

126

127

128

129

130

131

132

133

134

(http://www.rcsb.org/pdb/home/). We selected target proteins of interest by determining whether studies relating them to $\mathrm{AD}$ and crystal protein structures (with ligand present) were available. Inhibitors or agonists were used to confirm the ligands in the references we identified. We ultimately selected 30 target proteins. Information regarding the 30 target proteins, such as the Integrity name, corresponding name in the Uniprot database (http://www.uniprot.org/), Uniprot ID, PDB ID, ligand ID and document IDs in Pubmed and PMC are available in Supplementary Table 1. The 3D structures of the proteins are available as files in the pdb format. This format was converted to the pdbqt format using AutoDock tools v1.5.6 (Morris et al. 2009), and the 3D view was generated by Discovery Studio v3.1 (http://accelrys.com/products/collaborativescience/biovia-discovery-studio/).

\section{Molecular docking between natural compounds and AD target proteins}

Docking is tantamount to position the ligand in different orientations and conformations within the binding site to calculate optimal binding geometries and energies. Interactions between natural compounds and the $\mathrm{AD}$ target proteins were previously predicted using AutoDock Vina 1.1.2 (Trott \& Olson 2010). The docking binding site center for each target protein is the structural binding center of the ligand present in the crystal structure. The ligands were confirmed by the studies we identified. The coordinates of the docking center, ligand ID in PDB database and supporting documents are shown in Supplementary Table1. To allow free rotation of the compounds, the search space was set to $25 \times 25 \times 25 \AA$ in each axis. The default settings were used for all of the other docking parameters. Each docking was performed by a command that contained the space size and three-dimensional coordinate of the docking center. For each compound, the binding pose with the lowest energy for each docking test was considered the best binding mode. A lower energy score indicated a stronger binding affinity between the ligand and receptor. The compounds with the top $0.5 \%$ docking score were chosen as the candidate ligands for each target protein.

\section{Validation of the docking results}

To validate the docking results, three methods were used. First, we manually checked the 
135

136

137

138

139

140

141

142

143

144

145

146

147

148

149

150

151

152

153

154

155

156

157

158

159

160

161

docking results and visualized the interaction between the compound and receptor to verify that the compound was in the binding pocket. Second, the original ligand in the crystal structure was set as the reference. The docking energy of candidate anti-AD compounds should be better than or comparable to that of original ligand. Third, we check whether the top $0.5 \%$ TCM compounds are similar to the existing drugs that have been reported in anti-AD research.

Interactions among the target proteins, compounds and plants

The interaction between each target protein and its best-binding TCM compound was displayed using the PyMOL (PyMOL Molecular Graphics System, version 1.7) program (https://pymol.org). The pharmacophore was displayed using Discovery Studio v3.1.

The target-compound and target-plant networks were constructed using Cytoscape v3.4.0 (Shannon et al. 2003). In these networks, the target protein and compound were considered to be connected if the compound successfully docked to the target protein, and the target protein and the plant were considered to be connected if the plant with the compound was able to interact with the target protein. The strength of the links is represented by the line' thickness, which indicates the number of compounds shared between the target protein and plant.

\section{Collection of anti-AD plants from Chinese medicine prescription}

The term "senile dementia" was searched in the subject column of the CNKI database (http://www.cnki.net/) to retrieve Chinese medicine prescriptions for anti-AD from the relevant Chinese articles. Articles from clinical studies between 2007 and 2017 were selected. Chinese medicine prescriptions and the usage frequency were also obtained from these articles. The common anti-AD plants in traditional Chinese clinical medicines were identified from the prescriptions. For reference, Supplementary Table 2 shows information regarding the Chinese version of the raw prescription data with corresponding English, the Latin name of the anti-AD plants in each prescription, the patient number (male and female if available), the article title of the study, published data (years) and the article format.

\section{Similarity between candidate compounds and existing drugs}

The Tanimoto coefficient (Tc) and Pybel(O'Boyle et al. 2008) Python package were used to 
162

163

164

165

166

167

168

169

170

171

172

173

174

175

176

177

178

179

180

181

182

183

measure the structural similarities between compounds. The fingerprint FP2 implemented in Pybel was generated for each structure and used to calculate Tc. Tc is defined as $T c=C(i, j) / U(i$, $j)$, where $C(i, j)$ is the number of common features in the fingerprints of molecules $i$ and $j$ and $U(i$, $j$ ) is the number of all of the features in the union of the fingerprints of molecules $i$ and $j$. If the fingerprints of two compounds are $\mathrm{Tc}=1$, even if they differ among themselves by isolated instances of $\mathrm{C}, \mathrm{N}$ or $\mathrm{O}$ atoms, they will be considered structurally identical.

Cytoscape v3.4.0 was used to construct a network linking the candidate compounds, their target proteins and structurally identical drugs. A natural compound and an existing drug in the DrugBank database (Wishart et al. 2006) were considered to be connected, if their Tc score was 1. The natural compounds and their target proteins were also connected in this network.

\section{Clusters of potential candidate compounds for AD}

One-thousand-four-hundred-seventy-six compounds located in the top $0.5 \%$ of all compounds that docked with 30 target proteins were regarded as potential candidate compounds for AD. The cluster ligands protocol in BOVIA Pipeline Pilot V8.5

(http://accelrys.com/products/collaborative-science/biovia-pipeline-pilot/) was used to cluster the compounds. During clustering, a set of compounds was assigned to different clusters based on the similarity of their properties. Clustering was based on the root-mean-square (RMS) difference of the descriptor properties or the Tanimoto distance for fingerprints. In our study, we clustered the compounds based on the Tanimoto distance using the fingerprint FP2. Cluster ligands were performed by the number of size or the number of molecules per cluster. The default parameter in Pipeline Pilot V8.5 was set to fixed number of 10 clusters. For simplicity, we used default parameters to cluster our compounds. The molecule with the lowest total distance to all other members of the cluster was considered the cluster center.

\section{ADMET and $\log P$ properties for candidate compounds for AD}

The ADMET and $\log \mathrm{P}$ properties of candidate compounds for $\mathrm{AD}$ were estimated using Discovery Studio. ADMET refers to absorption, distribution, metabolism, excretion and toxicity and $\log \mathrm{P}$ refers to the logarithm of the partition coefficient. The ADMET properties, including 
189

190

191

192

193

194

195

196

197

198

199

200

201

202

203

204

205

206

207

208

209

210

211

212

213

214

215

aqueous solubility, blood brain barrier penetration (BBB), human intestinal absorption (HIA), plasma protein binding (PPB) and hepatotoxicity, as well as $\log \mathrm{P}$ were used to filter the compounds. The values of these properties were set as the controlled parameters, which were 3 4 (3: good; 4: optimal) for aqueous solubility, 1 2 (1: high; 2: medium) for BBB, 0 (0: good) for HIA, FALSE for both PPB and hepatotoxicity and $\log \mathrm{P}<5$.

\section{RESULTS}

\section{Molecular docking of natural compounds and embedded ligands to the 30 AD target}

\section{proteins}

Of the 60,000 compounds in the TCM Database, 30,438 contain plant information, and these compounds were docked with the 30 selected AD target proteins. The original ligands of each target protein were also docked to their corresponding target proteins. The docking results are shown in Table 1. The docking scores of ligands embedded in the protein crystal structure ranged from -3.31 to $-12.65(\mathrm{kcal} / \mathrm{mol})$. The lowest docking energy scores for the 30 target proteins ranged from -8.44 to $-14.5(\mathrm{kcal} / \mathrm{mol})$. Some target proteins, such as Caspase-3, QC, IDO and GLP-1R, were able to bind over 20,000 natural compounds with docking scores superior to those of their embedded ligands. However, the docking scores of the target RAR with natural compounds were inferior to those of its embedded ligand.

Because many TCM compounds can bind to AD target proteins, for each target protein, only the top $0.5 \%$ of compounds in terms of docking scores (a total of 1476 compounds) were selected as candidate compounds for AD. The original study of AutoDockVina showed that the success rate of Vina is $80 \%(\mathrm{RMSD}<2)$ for an independent validation dataset. Furthermore, Vina achieves a low standard error of $2.85 \mathrm{kcal} / \mathrm{mol}$ compared with the experimental free energies. There is a highly positive correlation between the predicted and experimental free energies of binding. In our study, almost all of the docking energies of the top $0.5 \%$ of compounds bound to target proteins were superior to those of their embedded ligands (Fig. 1).

Thus, the 1,476 compounds are likely candidate compounds for AD.

Analysis of the interactions between target proteins and ligands including TCM 
216

217

218

219

220

221

222

223

224

225

226

227

228

229

230

231

232

233

234

235

236

237

238

239

240

241

242

compounds, original ligands and approved AD drugs

The docking pose interactions between the target proteins and ligands including their bestbinding TCM compounds and original ligands are shown in Fig. 2A and Supplementary Fig. 1 to 29. The figures show side-by-side-comparisons of best TCM ligands and original ligands. The best TCM ligands and original ligands are located in the same binding pocket for each target protein and they all have some common residues. Taking AchE as an example: the best-binding TCM compound for AchE is 24829, the original ligand is Huperzine A, and their common residues are TYR-124, PHE-297, PHE-338, TYR-337, ASP-74. Furthermore, we compared the structures of the best-binding TCM compounds and previously known ligands (Supplementary Table 3) and found the structures to be different. The Tc scores are between 0.06 and 0.48 . Therefore, most of the best-binding TCM compounds are novel scaffolds.

We analyzed the pharmacophore of SIRT1 using the top 10 TCM compounds binding the target protein (Fig. 2B). The pharmacophore model consists of one hydrogen bond acceptor (HBA, green) and five hydrophobic centers (blue); therefore, we think that compounds that have this model may easily bind with SIRT1.

We also compared the docking energy scores between the approved AD drugs and the candidate compounds for the protein AchE (Supplementary Table 4). The approved AD drugs that we analyzed were Donepezil, Galantamine and Rivastigmine. All the three drugs were AchE inhibitors. The average docking energy score of the candidate compounds was superior to that of the approved AD drugs for the protein AchE. The docking pose interaction of the three drugs and the best-binding TCM compound with the protein AchE is shown in Supplementary Fig. 30. The three drugs and best-binding TCM compound were located in the same binding pocket, and their docking poses were different because their structures were different.

\section{Analysis of single-target and multi-target compounds}

Among the 1,476 candidate compounds for $\mathrm{AD}$, there were 850 compounds with a single target and 626 compounds with multiple targets (see Supplementary Fig. 31 and 32). The singletarget compounds corresponding to each target varied widely in number. For example, in single- 
243

244

245

246

247

248

249

250

251

252

253

254

255

256

257

258

259

260

261

262

263

264

265

266

267

268

269

target networks, target SIRT1 corresponds to 30 compounds, whereas target lyn just corresponds to 4 compounds. The multi-target compounds were classified into 18 networks based on their corresponding target numbers, which ranged from 2 to 24 . As the number of targets per compound increased, the number of compounds in that category decreased. For example, the two-target network contained 260 compounds, whereas the three-target and four-target networks contained 90 and 77 compounds, respectively. Finally, we observed that compound 24508 could bind to $25 \mathrm{AD}$ target proteins. The structure and network of compound 24508 are shown in Supplementary Fig. 32.

\section{Candidate AD compounds and their enrichment plants}

We mapped 1476 candidate $\mathrm{AD}$ compounds (corresponding to $30 \mathrm{AD}$ target proteins) to the 334 plants. The plant numbers for each target protein ranged from 42 to 71 , whereas the compound numbers for each target protein ranged from 62 to 132 (Fig. 3 and Supplementary Fig. $33)$.

We selected 101 clinically related studies out of over 10,000 senile dementia-related articles and identified 141 anti-AD traditional Chinese plants from the clinical prescriptions in these articles. The 141 traditional Chinese anti-AD plants were classified based on their functional properties in the TCM database. Most of the 141 anti-AD plants were in the 'Tonifying, Replenishing' category, and the plants in this category accounted for $28.45 \%$ of all anti-AD plants (Supplementary Fig. 34).

The best-associated plant for each target protein contained the greatest number of compounds capable of docking with the target protein (Table 2 and Fig. 4). The number of compounds in Table 2 was based on the top $0.5 \%$ of compounds successfully docking to each target protein. Thus, 30 target proteins corresponded to 16 best-associated plants, of which the top 5 plants were anti-AD traditional Chinese plants, including Panax and Morus, which corresponded to 7 and 5 target proteins, respectively, as well as Salvia, Rheum and Paeonia.

\section{Similarities between candidate compounds and existing drugs}

A structural comparison between all existing approved drugs recorded in the DrugBank and 
270 the top $0.5 \%$ of the natural compounds tested demonstrated that some compounds were identical 271 to existing drugs $(\mathrm{Tc}=1)$. The connection network among candidate compounds, existing drugs 272 and $\mathrm{AD}$ target proteins was established, and the chemical structures of the compounds are also 273 shown in Fig. 5. There were 17 candidate compounds, 14 existing drugs and 25 AD-associated

274

275

276

277

278

279

280

281

282

283

284

285

286

287

288

289

290

291

292

293

294

295

296 target proteins in the network. The 14 drugs included Lutein (DB00137), Vitamin A (DB00162), Vitamin E (DB00163), Azelaic Acid (DB00548), Ergotamine (DB00696), Estradiol (DB00783), Menthol (DB00825), Drostanolone (DB00858), Glyburide (DB01016), Tubocurarine (DB01199), Metocurine (DB01336), Yohimbine (DB01392), Lactose (DB04465), Artemether (DB06697).

Most of the drugs listed above have been reported to have a positive effect in AD. Some studies have shown that Lutein is involved in preventing cognitive decline and decreasing the risk of AD; thus, Lutein may contribute to the treatment of AD (Kiko et al. 2012; Min \& Min 2014; Xu \& Lin 2015). Similarly, Vitamin A, Vitamin E, Estradiol, Menthol, Glyburide and Yohimbine are also considered useful in the prevention and treatment of AD (Bhadania et al. 2012; Dysken et al. 2014; Lamkanfi et al. 2009; Lan et al. 2016; Mohamd et al. 2011; Ono \& Yamada 2012; Peskind et al. 1995; Takasaki et al. 2011). Therefore, compounds with structures similar to the existing drugs may also have anti-AD function by interacting with similar target proteins.

Of the 17 candidate compounds, 11 can only bind with one target protein, whereas the rest, which are similar to the 14 drugs discussed above, can interact with more than one target protein. For example, compound 18491 which is similar to Menthol can only interact with the target Ftase and compounds 19476 and 19477 are similar to Tubocurarine and Metocurine, respectively, whereas compound 18582 which is similar to Ergotamine can bind with 17 target proteins.

\section{Structure clusters of candidate AD compounds}

To compare the structural features of the candidate AD compounds, the 1,476 candidate compounds were assigned to 10 clusters. The structures of the cluster center compounds and maximal common substructure of each cluster are shown in Fig. 6. The Generate Maximal Common Substructure component must contain the proportion of the cluster molecules. The 
297 proportion was set to 0.5 to find the largest maximal common substructure that was contained in 298 at least $50 \%$ of the cluster molecules. All of the compounds in the center of the cluster contained

299 the carbocyclic structure, similar to the five approved drugs for AD. The cluster sizes varied, 300 with the largest containing 464 compounds and the smallest containing only 6 compounds. Every 301 cluster had a primary target protein that could better combine with the compounds in the cluster. 302 The binding of the best member of the cluster to the primary target protein and their structures 303 are also shown in Fig. 6.

To see if there were similar or different scaffolds able to bind each target protein, clusters in

305

306

307

308

309

310

311

312

313

314

315

316

317

318

319

320

321

322

323

the sets of ligands that bind to each individual protein were shown in Supplementary Table 5 to

34. Each set of ligands was assigned to 10 clusters. The compounds in the center of the cluster do not have the same scaffolds for each individual protein.

\section{1 candidate compounds for AD with favorable ADMET and $\log P$ properties}

Most orally approved drugs have favorable druggability properties. After ADMET and $\log P$ filtering, 11 compounds from 1476 candidate anti-AD compounds possessed favorable properties (Table 3). The 11 compounds all have good HIA and don't have PPB and hepatotoxicity. Compound 28468 has optimal aqueous solubility. And compound 16167 has high BBB. Of the 11 compounds, 8 were single-target compounds, and the remaining 3 were multi-target compounds. For example, compounds 5868, 9593, 10639, 28814 and 30713 could only bind with one target protein (GABA(B), MAOB, PDE4, RAR and MAOA, respectively), whereas compounds 5862, 5869 and 16167 shared one common target (AchE). Compound 5863 was able to bind with three target proteins (AchE, GABA(B) and MGLUR), and compound 26629 and 28468 were able to interact with five target proteins. These 11 compound structures and their corresponding plants are shown in Fig. 7. The plants corresponding to 7 of these compounds are regarded as anti-AD plants in TCM, including Curcuma kwangsiensis, Poria cocos, Lindera aggregate, Ophiopogon japonicus (L.f.) Ker-Gawl. and Glycyrrhiza glabra. 11 compounds belong to different organic compound classes. Compounds 5862, 5863, 5868, 5869 belong to linear diarylheptanoids. Compound 10639, 16167, 26629, 28468, 28814, 30713 belongs to 
324

325

326

327

328

329

330

331

332

333

guanidines, pyridines, hydrophenanthrenes, angular pyranocoumarins, naphthyridines, 8prenylated isoflavanones, respectively. We also checked the 11 comopund structures and existing research in pubchem database. Compounds 5862, 5863, 5868, 5869 have antiinflammatory activity and compound 28814 mainly has immunoregulatory activity. The other 6 compounds have not yet been reported for any biology activity at present.

\section{DISCUSSION}

Candidate compounds from traditional Chinese plants provide a broad prospect for screening anti-AD drugs. We established a network between compounds in traditional Chinese plants and a comprehensive list of anti-AD target proteins involved in various hypotheses. This network, which links compounds, TCM plants and target proteins, may be very helpful for anti-AD drug design.

During our manual assessment of the binding pockets and modes of compounds, we discovered that some receptor had a large binding pocket and some had their binding pocket exposed on the surface. Therefore, the number of successfully docked compounds for these receptors is more than that of other receptors. This result suggests that for these receptors, there may be many false positive compounds that do not bind to the receptor. Thus, we choose TCM compounds with top $0.5 \%$ docking scores as our objects to avoid false positive compounds that do not bind to the receptor.

ADMET is an important index in drug development. After filtering the compounds according to five ADMET properties, 11 candidate anti-AD compounds with novel structures remained. Among the 11 compounds, 8 were single-target compounds and the remaining 3 had more than two target proteins. The structures and target proteins of these compounds are known, so they can be easily studied in future drug development, because these compounds have favorable druggability properties, they may become the promising candidate drugs for AD. Of course, further experiments are necessary to establish their viability as real candidate drugs.

Many compounds that bind to AD-associated target proteins were observed in plants that have not been used to treat $\mathrm{AD}$ in traditional Chinese clinical prescription. Thus, some 
351 previously non-anti-AD plants may become the anti-AD plants, which will provide more natural 352 compound resources for AD drug discovery and be will also be beneficial for the development of 353 TCMs.

\section{CONCLUSION}

355 In summary, this study offers one strategy to find novel candidate anti-AD drugs from 356 traditional Chinese plants by constructing interaction networks between AD target proteins and 357 natural compounds in TCM plants. We got a total of 1476 drug candidates (top $0.5 \%$ docked 358 compounds for each target) using this strategy. Of 1476 drug candidates, 17 candidate anti-AD 359 compounds were structurally identical to 14 existing approved drugs. In addition, 11 anti-AD 360 candidate compounds with favorable ADMET and $\log P$ properties were identified. Of 11 361 identified compounds, 4 compounds have anti-inflammatory activity, including compounds 5862, $3625863,5868,5869$ and compound 28814 mainly has immunoregulatory activity. Other 6 compounds have not bioassay research in pubchem database at present. Further experiments are needed to verify our drug candidates. This strategy and identified drug candidates may be helpful 365 for anti-AD drug discovery.

\section{ACKNOWLEDGMENTS}

We thank our colleagues, Drs. Yi-Cheng Guo and Shun-Mei Chen for helpful comments on 368 the manuscript. We also thank four reviewers for valuable comments. 
370

371

372

373

374

375

376

377

378

379

380

381

382

383

384

385

386

387

388

389

390

391

392

393

394

395

396

397

398

399

400

401

402

403

404

405

406

407

408

409

410

\section{REFERENCES}

Armstrong RA. 2013. What causes Alzheimer's disease? Folia Neuropathologica 51:169-188. 10.5114/fn.2013.37702

Azam F, Amer AM, Abulifa AR, and Elzwawi MM. 2014. Ginger components as new leads for the design and development of novel multi-targeted anti-Alzheimer's drugs: a computational investigationle. Drug Design Development and Therapy 8:2045-2059.

Bezprozvanny I, and Mattson MP. 2008. Neuronal calcium mishandling and the pathogenesis of Alzheimer's disease. Trends Neurosci 31:454-463. 10.1016/j.tins.2008.06.005

Bhadania M, Joshi H, Patel P, and Kulkarni VH. 2012. Protective effect of menthol on betaamyloid peptide induced cognitive deficits in mice. European Journal of Pharmacology 681:50-54. 10.1016/j.ejphar.2012.01.035

Bonda DJ, Lee HG, Blair JA, Zhu X, Perry G, and Smith MA. 2011. Role of metal dyshomeostasis in Alzheimer's disease. Metallomics 3:267-270. 10.1039/c0mt00074d

Cai Z, Liu N, Wang C, Qin B, Zhou Y, Xiao M, Chang L, Yan LJ, and Zhao B. 2016. Role of RAGE in Alzheimer's Disease. Cell Mol Neurobiol 36:483-495. 10.1007/s10571-0150233-3

Chen CY. 2011. TCM Database@Taiwan: the world's largest traditional Chinese medicine database for drug screening in silico. PLoS One 6:e15939. 10.1371/journal.pone.0015939

Coyle JT, Price DL, and DeLong MR. 1983. Alzheimer's disease: a disorder of cortical cholinergic innervation. Science 219:1184-1190.

Craig LA, Hong NS, and McDonald RJ. 2011. Revisiting the cholinergic hypothesis in the development of Alzheimer's disease. Neurosci Biobehav Rev 35:1397-1409. 10.1016/j.neubiorev.2011.03.001

Cummings JL, Morstorf T, and Zhong K. 2014. Alzheimer's disease drug-development pipeline: few candidates, frequent failures. Alzheimers Res Ther 6:37. 10.1186/alzrt269

Darvesh S. 2016. Butyrylcholinesterase as a Diagnostic and Therapeutic Target for Alzheimer's Disease. Current Alzheimer Research 13:1173-1177. $10.2174 / 1567205013666160404120542$

Deane RJ. 2012. Is RAGE still a therapeutic target for Alzheimer's disease? Future Medicinal Chemistry 4:915-925. 10.4155/Fmc.12.51

Dickson DW. 1997. Neuropathological diagnosis of Alzheimer's disease: a perspective from longitudinal clinicopathological studies. Neurobiol Aging 18:S21-26.

Dysken MW, Sano M, Asthana S, Vertrees JE, Pallaki M, Llorente M, Love S, Schellenberg GD, McCarten JR, Malphurs J, Prieto S, Chen P, Loreck DJ, Trapp G, Bakshi RS, Mintzer JE, Heidebrink JL, Vidal-Cardona A, Arroyo LM, Cruz AR, Zachariah S, Kowall NW, Chopra MP, Craft S, Thielke S, Turvey CL, Woodman C, Monnell KA, Gordon K, Tomaska J, Segal Y, Peduzzi PN, and Guarino PD. 2014. Effect of vitamin E and memantine on functional decline in Alzheimer disease: the TEAM-AD VA cooperative randomized trial. JAMA 311:33-44. 10.1001/jama.2013.282834

Fan LY, and Chiu MJ. 2014. Combotherapy and current concepts as well as future strategies for the treatment of Alzheimer's disease. Neuropsychiatric Disease and Treatment 10:439- 
411

412

413

414

415

416

417

418

419

420

421

422

423

424

425

426

427

428

429

430

431

432

433

434

435

436

437

438

439

440

441

442

443

444

445

446

447

448

449

450

451

451. 10.2147/Ndt.S45143

Gentile MT, Reccia MG, Sorrentino PP, Vitale E, Sorrentino G, Puca AA, and Colucci-D'Amato L. 2012. Role of cytosolic calcium-dependent phospholipase A2 in Alzheimer's disease pathogenesis. Mol Neurobiol 45:596-604. 10.1007/s12035-012-8279-4

Goedert M, and Spillantini MG. 2006. A century of Alzheimer's disease. Science 314:777-781. $10.1126 /$ science. 1132814

Kiko T, Nakagawa K, Tsuduki T, Suzuki T, Arai H, and Miyazawa T. 2012. Significance of lutein in red blood cells of Alzheimer's disease patients. J Alzheimers Dis 28:593-600. 10.3233/JAD-2011-111493

Lamkanfi M, Mueller JL, Vitari AC, Misaghi S, Fedorova A, Deshayes K, Lee WP, Hoffman HM, and Dixit VM. 2009. Glyburide inhibits the Cryopyrin/Nalp3 inflammasome. $J$ Cell Biol 187:61-70. 10.1083/jcb.200903124

Lan YL, Zou S, Zhang C, Li J, Xu Y, and Li S. 2016. Update on the effect of estradiol in postmenopause women with Alzheimer's disease: a systematic review. Acta Neurol Belg 116:249-257. 10.1007/s13760-015-0593-y

Lee JC, Simonyi A, Sun AY, and Sun GY. 2011. Phospholipases A2 and neural membrane dynamics: implications for Alzheimer's disease. J Neurochem 116:813-819. 10.1111/j.1471-4159.2010.07033.x

Leszek J, Barreto GE, Gasiorowski K, Koutsouraki E, Avila-Rodrigues M, and Aliev G. 2016. Inflammatory Mechanisms and Oxidative Stress as Key Factors Responsible for Progression of Neurodegeneration: Role of Brain Innate Immune System. Cns \& Neurological Disorders-Drug Targets 15:329-336. $10.2174 / 1871527315666160202125914$

Mattson MP. 2004. Pathways towards and away from Alzheimer's disease (vol 430, pg 631, 2004). Nature 431:107-107. 10.1038/nature02940

Min JY, and Min KB. 2014. Serum lycopene, lutein and zeaxanthin, and the risk of Alzheimer's disease mortality in older adults. Dement Geriatr Cogn Disord 37:246-256. $10.1159 / 000356486$

Mohamd EM, Ahmed HH, Estefan SF, Farrag AERH, and Salah RS. 2011. Windows into estradiol effects in Alzheimer's disease therapy. European Review for Medical and Pharmacological Sciences 15:1131-1140.

Morris GM, Huey R, Lindstrom W, Sanner MF, Belew RK, Goodsell DS, and Olson AJ. 2009. AutoDock4 and AutoDockTools4: Automated docking with selective receptor flexibility. J Comput Chem 30:2785-2791. 10.1002/jcc.21256

Mushtaq G, Greig NH, Khan JA, and Kamal MA. 2014. Status of acetylcholinesterase and butyrylcholinesterase in Alzheimer's disease and type 2 diabetes mellitus. CNS Neurol Disord Drug Targets 13:1432-1439.

Normile D. 2003. Asian medicine. The new face of traditional Chinese medicine. Science 299:188-190. 10.1126/science.299.5604.188

O'Boyle NM, Banck M, James CA, Morley C, Vandermeersch T, and Hutchison GR. 2011. Open Babel: An open chemical toolbox. J Cheminform 3:33. 10.1186/1758-2946-3-33 
452

453

454

455

456

457

458

459

460

461

462

463

464

465

466

467

468

469

470

471

472

473

474

475

476

477

478

479

480

481

482

483

484

485

486

487

488

489

490

491

492

O'Boyle NM, Morley C, and Hutchison GR. 2008. Pybel: a Python wrapper for the OpenBabel cheminformatics toolkit. Chem Cent J 2:5. 10.1186/1752-153X-2-5

Ono K, and Yamada M. 2012. Vitamin A and Alzheimer's disease. Geriatr Gerontol Int 12:180188. 10.1111/j.1447-0594.2011.00786.x

Peng X, Xing P, Li X, Qian Y, Song F, Bai Z, Han G, and Lei H. 2016. Towards Personalized Intervention for Alzheimer's Disease. Genomics Proteomics Bioinformatics 14:289-297. 10.1016/j.gpb.2016.01.006

Peskind ER, Wingerson D, Murray S, Pascualy M, Dobie DJ, Le Corre P, Le Verge R, Veith RC, and Raskind MA. 1995. Effects of Alzheimer's disease and normal aging on cerebrospinal fluid norepinephrine responses to yohimbine and clonidine. Arch Gen Psychiatry 52:774-782.

Pratico D. 2008. Oxidative stress hypothesis in Alzheimer's disease: a reappraisal. Trends in Pharmacological Sciences 29:609-615. 10.1016/j.tips.2008.09.001

Sanderson K. 2011. Databases aim to bridge the East-West divide of drug discovery. Nat Med 17:1531. 10.1038/nm1211-1531a

Shannon P, Markiel A, Ozier O, Baliga NS, Wang JT, Ramage D, Amin N, Schwikowski B, and Ideker T. 2003. Cytoscape: a software environment for integrated models of biomolecular interaction networks. Genome Res 13:2498-2504. 10.1101/gr.1239303

Shen J, and Wu J. 2015. Nicotinic Cholinergic Mechanisms in Alzheimer's Disease. Int Rev Neurobiol 124:275-292. 10.1016/bs.irn.2015.08.002

Song F, Han G, Bai Z, Peng X, Wang J, and Lei H. 2015. Alzheimer's Disease: Genomics and Beyond. Int Rev Neurobiol 121:1-24. 10.1016/bs.irn.2015.05.001

Sucher NJ. 2013. The application of Chinese medicine to novel drug discovery. Expert Opin Drug Discov 8:21-34. 10.1517/17460441.2013.739602

Sun Y, Zhu RX, Ye H, Tang KL, Zhao J, Chen YJ, Liu Q, and Cao ZW. 2013. Towards a bioinformatics analysis of anti-Alzheimer's herbal medicines from a target network perspective. Briefings in Bioinformatics 14:327-343. 10.1093/bib/bbs025

Takasaki J, Ono K, Yoshiike Y, Hirohata M, Ikeda T, Morinaga A, Takashima A, and Yamada M. 2011. Vitamin A has Anti-Oligomerization Effects on Amyloid-beta In Vitro. Journal of Alzheimers Disease 27:271-280. 10.3233/Jad-2011-110455

Trepanier CH, and Milgram NW. 2010. Neuroinflammation in Alzheimer's disease: are NSAIDs and selective COX-2 inhibitors the next line of therapy? J Alzheimers Dis 21:1089-1099.

Trott O, and Olson AJ. 2010. AutoDock Vina: improving the speed and accuracy of docking with a new scoring function, efficient optimization, and multithreading. J Comput Chem 31:455-461. 10.1002/jcc.21334

Wishart DS, Knox C, Guo AC, Shrivastava S, Hassanali M, Stothard P, Chang Z, and Woolsey J. 2006. DrugBank: a comprehensive resource for in silico drug discovery and exploration. Nucleic Acids Res 34:D668-672. 10.1093/nar/gkj067

Wyss-Coray T, and Rogers J. 2012. Inflammation in Alzheimer disease-a brief review of the basic science and clinical literature. Cold Spring Harb Perspect Med 2:a006346. 10.1101/cshperspect.a006346

PeerJ reviewing PDF | (2017:11:21844:2:1:NEW 11 Apr 2018) 
$493 \mathrm{Xu} \mathrm{X}$, and Lin X. 2015. [Advances in the researches of lutein and alzheimer's disease].

494 Zhonghua Yu Fang Yi Xue Za Zhi 49:456-460.

495 Yiannopoulou KG, and Papageorgiou SG. 2013. Current and future treatments for Alzheimer's 496 disease. Ther Adv Neurol Disord 6:19-33. 10.1177/1756285612461679

497 


\section{Table $\mathbf{1}$ (on next page)}

Details of the docking results of 30 anti-AD targets with the number of successfully docked TCM compounds 
1 Table 1. Details of the docking results of 30 anti-AD targets with the number of successfully 2 docked TCM compounds

\begin{tabular}{|c|c|c|c|c|c|}
\hline $\begin{array}{l}\text { RCSB } \\
\text { ID }\end{array}$ & Protein Name & $\begin{array}{c}\text { Original } \\
\text { Ligands ID }\end{array}$ & $\begin{array}{c}\text { Binding Energy } \\
\text { of Original } \\
\text { Ligand }^{\mathrm{a}}\end{array}$ & $\begin{array}{c}\text { Lowest } \\
\text { Docking } \\
\text { Energy }\end{array}$ & $\begin{array}{l}\text { Compound } \\
\text { Number }^{b}\end{array}$ \\
\hline 1DB4 & $\begin{array}{c}\text { PLA2(Phospholipase A2, membrane } \\
\text { associated) }\end{array}$ & $8 \mathrm{IN}$ & -7.31 & -11.55 & 5290 \\
\hline 1DQA & $\begin{array}{l}\text { HMG-COA(3-hydroxy-3-methylglutaryl- } \\
\text { coenzyme A reductase) }\end{array}$ & NAP & -7.42 & -9.78 & 437 \\
\hline $1 \mathrm{NME}$ & Caspase-3 & 159 & -4.57 & -10.24 & 21028 \\
\hline 1OJA & $\begin{array}{l}\text { MAOB(Amine oxidase [flavin- } \\
\text { containing] B) }\end{array}$ & ISN & -6.58 & -12.2 & 11173 \\
\hline 1TB7 & $\begin{array}{l}\text { PDE4(cAMP-specific 3',5'-cyclic } \\
\text { phosphodiesterase 4D) }\end{array}$ & AMP & -6.47 & -14.5 & 17375 \\
\hline 1TN6 & $\begin{array}{l}\text { Ftase(Protein farnesyltransferase subunit } \\
\text { beta) }\end{array}$ & FII & -6.59 & -11.9 & 14437 \\
\hline $2 \mathrm{AFW}$ & QC(Glutaminyl-peptide cyclotransferase) & $\mathrm{AHN}$ & -4.48 & -11.11 & 23635 \\
\hline $2 \mathrm{AZ5}$ & TNF(Tumor necrosis factor) & 307 & -5.66 & -9.53 & 9261 \\
\hline 2D0T & IDO(Indoleamine 2,3-dioxygenase 1) & PIM & -5.71 & -12.4 & 20739 \\
\hline 2DQ7 & Fyn(Tyrosine-protein kinase Fyn) & STU & -10.28 & -12.41 & 63 \\
\hline 2VQM & HDAC(Histone deacetylase 4) & HA3 & -7.11 & -11.33 & 5356 \\
\hline $2 \mathrm{Z} 5 \mathrm{Y}$ & $\begin{array}{l}\text { MAOA (Amine oxidase [flavin- } \\
\text { containing] A) }\end{array}$ & HRM & -7.96 & -12.8 & 5299 \\
\hline $3 \mathrm{~A} 4 \mathrm{O}$ & lyn(Tyrosine-protein kinase Lyn) & STU & -9.4 & -12.53 & 431 \\
\hline $3 \mathrm{G} 9 \mathrm{~N}$ & JNK(Mitogen-activated protein kinase 10) & J88 & -7.19 & -10.36 & 1606 \\
\hline 3IKA & EGFR(Epidermal growth factor receptor) & OUN & -7.64 & -11.45 & 6324 \\
\hline $3 \mathrm{KMR}$ & RAR(Retinoic acid receptor alpha) & EQN & -12.65 & -11.4 & 0 \\
\hline $3 \mathrm{O} 3 \mathrm{U}$ & $\begin{array}{l}\text { RAGE(Advanced glycosylation end } \\
\text { product-specific receptor) }\end{array}$ & MLR & -7.76 & -14.08 & 13309 \\
\hline 4DJU & BACE-1(Beta-secretase 1) & $0 \mathrm{KK}$ & -7.12 & -12.2 & 14161 \\
\hline $4 \mathrm{EY} 5$ & AchE(Acetylcholinesterase) & HUP & -8.5 & -10.6 & 329 \\
\hline 4MS4 & $\begin{array}{l}\text { GABA }(B)(\text { Gamma-aminobutyric acid } \\
\text { type B receptor subunit } 1)\end{array}$ & $2 \mathrm{C} 0$ & -5.73 & -10.6 & 13107 \\
\hline $4 \mathrm{OC} 7$ & RXR(Retinoic acid receptor RXR-alpha) & 2QO & -8.48 & -11.3 & 708 \\
\hline 4XAR & $\begin{array}{l}\text { MGLUR(Metabotropic glutamate receptor } \\
\text { 3) }\end{array}$ & $40 \mathrm{~F}$ & -4.98 & -8.5 & 9244 \\
\hline 4YLK & $\begin{array}{l}\text { DYRK1A(Dual specificity tyrosine- } \\
\text { phosphorylation-regulated kinase 1A) }\end{array}$ & $4 \mathrm{E} 2$ & -8.13 & -12.54 & 7167 \\
\hline 4ZGM & $\begin{array}{l}\text { GLP-1R(Glucagon-like peptide } 1 \\
\text { receptor) }\end{array}$ & $32 \mathrm{M}$ & -3.31 & -9.06 & 24782 \\
\hline 4ZZJ & SIRT1(NAD-dependent protein & 4TQ & -6.89 & -8.86 & 108 \\
\hline
\end{tabular}




\begin{tabular}{|c|c|c|c|c|c|}
\hline & deacetylase sirtuin-1) & & & & \\
\hline $5 \mathrm{~A} 46$ & $\begin{array}{l}\text { FGFR1(Fibroblast growth factor receptor } \\
\text { 1) }\end{array}$ & 380 & -8.54 & -12.8 & 699 \\
\hline $5 \mathrm{AFH}$ & $\begin{array}{l}\alpha 7 \mathrm{NACHR}(\text { Neuronal acetylcholine } \\
\text { receptor subunit alpha-7) }\end{array}$ & L0B & -6.02 & -9.64 & 6934 \\
\hline $5 \mathrm{H} 8 \mathrm{~S}$ & AMPA(Glutamate receptor 2) & $5 \mathrm{YC}$ & -5.3 & -8.44 & 8926 \\
\hline $5 \mathrm{HK} 1$ & $\begin{array}{l}\text { SIG-1R(Sigma non-opioid intracellular } \\
\text { receptor } 1)\end{array}$ & $61 \mathrm{~W}$ & -9.29 & -12.8 & 1281 \\
\hline $5 \mathrm{IH} 5$ & $\mathrm{CKI}-\delta($ Casein kinase I isoform delta) & AUE & -7.62 & -12.5 & 5998 \\
\hline
\end{tabular}

3 a. 'Binding Energy of Original Ligand' indicates the docking energy of the ligand embedded in 4 the crystal structure.

5 b. The number of compounds with better docking scores than that of the original ligand 6 embedded in the crystal structure. 
Table 2 (on next page)

$A D$ targets and their best-associated plant with the most compounds docking with the target 
1 Table 2. AD targets and their best-associated plant with the most compounds docking with the 2 target

\begin{tabular}{cccccc}
\hline Target & Top1 Plant & Target & Top1 Plant & Target & Top1 Plant \\
\hline PLA2 & Bletilla(5)a & HMG-COA & Morus(9) & Caspase-3 & Paeonia(4) \\
MAOB & Corydalis(16) & PDE4 & Isatis(4) & Ftase & Panax(8) \\
QC & Panax(4) & TNF & Panax(10) & IDO & Morus(7) \\
Fyn & Papaver(11) & HDAC & Bletilla(5) & MAOA & Corydalis(11) \\
lyn & Claviceps(5) & JNK & Morus(8) & EGFR & Artemisia(7) \\
RAR ${ }^{b}$ & Rauwolfia(8) & RAGE & Fritillaria(7) & BACE-1 & Lonicera(6) \\
AchE & Piper(6) & SIRT1 & Panax(18) & GABA(B) & Morus(11) \\
RXR & Salvia(10) & MGLUR & Morus(4) & DYRK1A & Strychnos(6) \\
GLP-1R & Panax(9) & FGFR1 & Rheum(6) & $\alpha 7 N A C H R ~$ & Panax(8) \\
AMPA & Panax(7) & SIG-1R & Corydalis(7) & CKI- $\delta$ & Salvia(11) \\
\hline
\end{tabular}

3 a. The numbers in this table are compound numbers which the best-associated plant for each 4 target protein contains.

5 b. The docking energy of TCM compounds is higher than that of the original ligand for RAR 6 protein. 
Table 3(on next page)

ADMET and $\log P$ properties of 11 candidate drugs 
1 Table 3. ADMET and $\log P$ properties of 11 candidate drugs

\begin{tabular}{|c|c|c|c|c|c|c|c|}
\hline Name(ID) & $\begin{array}{l}\text { Solubility } \\
\text { Level }\end{array}$ & $\begin{array}{c}\text { BBB } \\
\text { Level }\end{array}$ & $\begin{array}{c}\text { Hepatotoxic } \\
\text { Prediction }\end{array}$ & $\begin{array}{l}\text { Absorption } \\
\text { Level }\end{array}$ & $\begin{array}{c}\text { PPB } \\
\text { Prediction }\end{array}$ & $\log P$ & Targets \\
\hline $\begin{array}{c}\text { (3S)-1-(3,4- } \\
\text { Dihydroxyphenyl)-7-(4- } \\
\text { hydroxyphenyl)heptan-3- } \\
\text { ol(5862) }\end{array}$ & 3 & 2 & FALSE & 0 & FALSE & 4.578 & AchE \\
\hline $\begin{array}{l}\text { (3S)-1-(3,4- } \\
\text { Dihydroxyphenyl)-7-(4- } \\
\text { hydroxyphenyl)-(6E)-6- } \\
\text { hepten-3-ol(5863) }\end{array}$ & 3 & 2 & FALSE & 0 & FALSE & 4.134 & $\begin{array}{l}\text { AchE,GABA } \\
\text { (B),MGLUR }\end{array}$ \\
\hline $\begin{array}{l}\text { (3R)-1-(3,4- } \\
\text { Dihydroxyphenyl)-7-(4- } \\
\text { hydroxyphenyl)heptan-3- } \\
\text { ol(5868) }\end{array}$ & 3 & 2 & FALSE & 0 & FALSE & 4.578 & $\mathrm{GABA}(\mathrm{B})$ \\
\hline $\begin{array}{l}\quad(3 \mathrm{R})-1-(3,4- \\
\text { Dihydroxyphenyl)-7-(4- } \\
\text { hydroxyphenyl)-(6E)-6- } \\
\text { hepten-3-ol(5869) }\end{array}$ & 3 & 2 & FALSE & 0 & FALSE & 4.134 & AchE \\
\hline pallidine(9593) & 3 & 2 & FALSE & 0 & FALSE & 1.913 & MAOB \\
\hline $\begin{array}{c}\text { 4,5-di-o- } \\
\text { caffeoyl,quinic,acid(10639) }\end{array}$ & 3 & 2 & FALSE & 0 & FALSE & 3.477 & PDE4 \\
\hline Anagyrine(16167) & 3 & 1 & FALSE & 0 & FALSE & 2.053 & AchE \\
\hline Blestrin D(26629) & 3 & 2 & FALSE & 0 & FALSE & 4.578 & $\begin{array}{c}\text { PLA2,QC,H } \\
\text { DAC,JNK,G } \\
\text { ABA(B) }\end{array}$ \\
\hline Dibothrioclinin II(28468) & 4 & 2 & FALSE & 0 & FALSE & 1.222 & $\begin{array}{c}\text { Ftase,QC,HD } \\
\text { AC,GLP- } \\
\text { 1R,AMPA }\end{array}$ \\
\hline $\begin{array}{l}\text { 5,7-Dihydroxy-6,8- } \\
\text { dimethyl-3-(4'-hydroxy-3'- } \\
\text { methoxybenzyl)chroman-4- } \\
\text { one }(28814)\end{array}$ & 3 & 2 & FALSE & 0 & FALSE & 1.144 & RAR \\
\hline $\begin{array}{l}\text { Glabroisoflavanone } \\
\qquad \mathrm{A}(30713)\end{array}$ & 3 & 2 & FALSE & 0 & FALSE & 1.913 & MAOA \\
\hline
\end{tabular}


Figure 1

The docking energy scores of the top $0.5 \%$ TCM compounds and original ligands for 30 targets

Red boxes represent the top $0.5 \%$ of compounds for each target protein. Blue points represent the target proteins' embedded ligands.

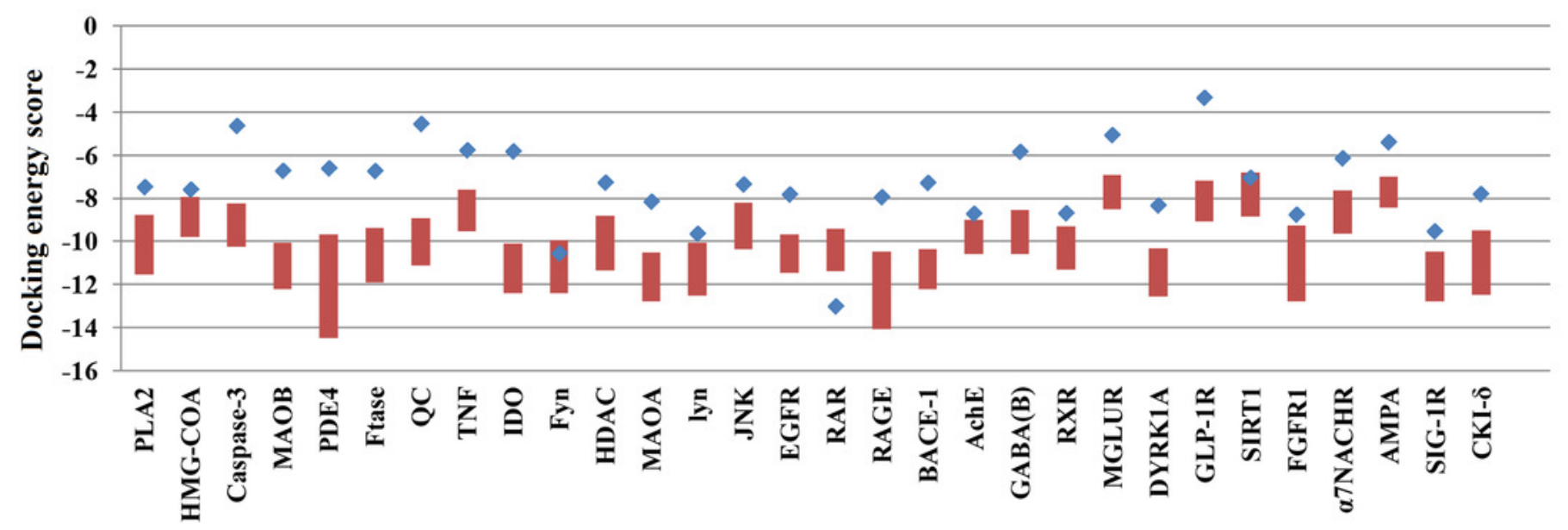




\section{Figure 2}

The docking pose interactions between the target proteins and ligands including their best-binding TCM compounds and original ligands and the pharmacophore of SIRT1

A. The 3D structures and binding model of ligands including best ligand and original ligand to the target protein AchE. The best ligand is green and the original ligand is magenta. The top panel shows the amino acid residues lying within $5 \AA$ from the best ligand, and the bottom panel shows the amino acid residues lying within $5 \AA$ from the original ligand.

B. The pharmacophore of SIRT1 using top 10 TCM compounds binding for the target protein. The hydrogen bond acceptor is in green and the hydrophobic centers are in blue. 


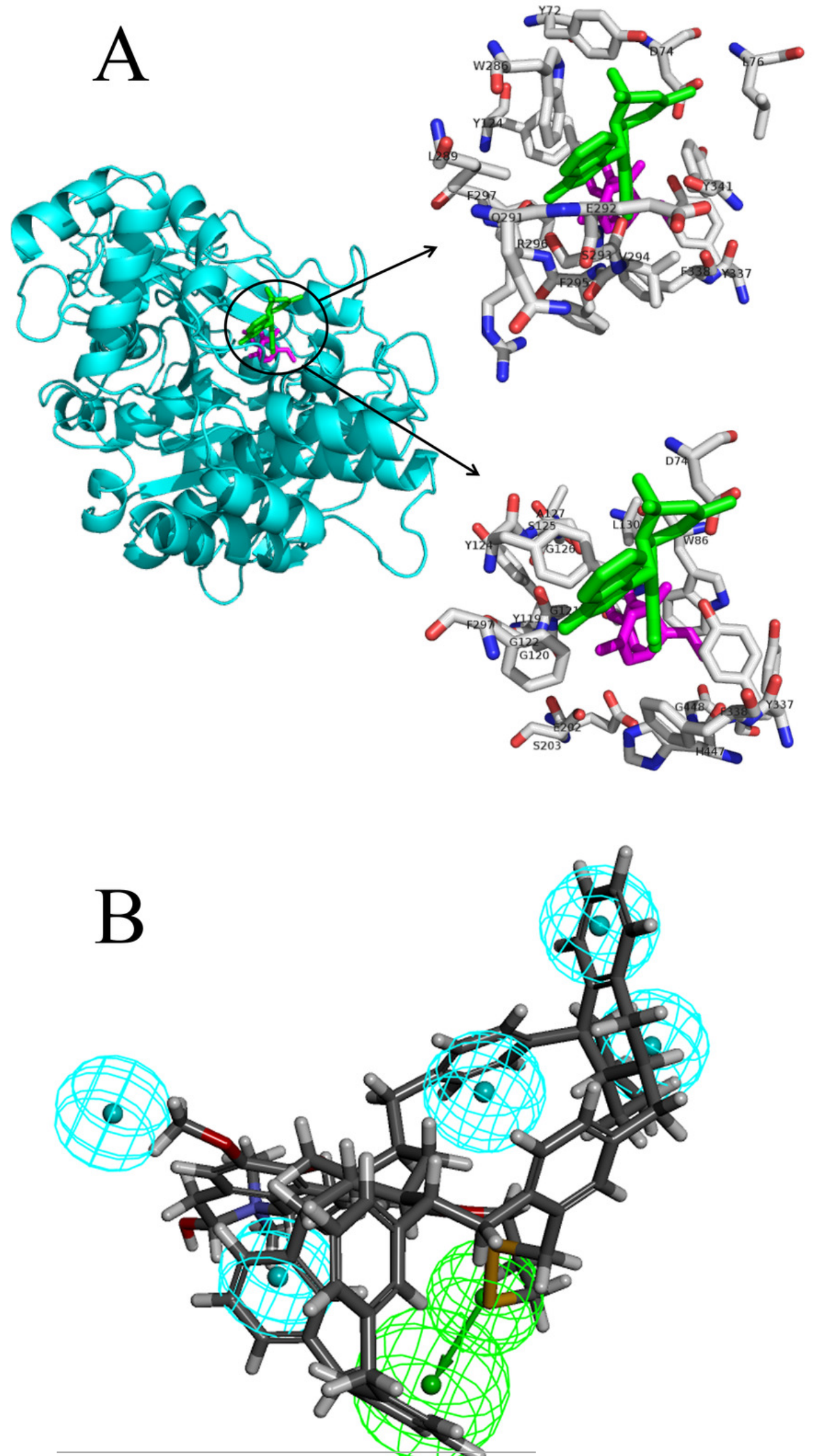


Figure 3

The exact number of candidate anti-AD compounds and their plants associated with each anti-AD target protein.

The number is tagged above each column, and the target proteins are displayed on the horizontal axis.

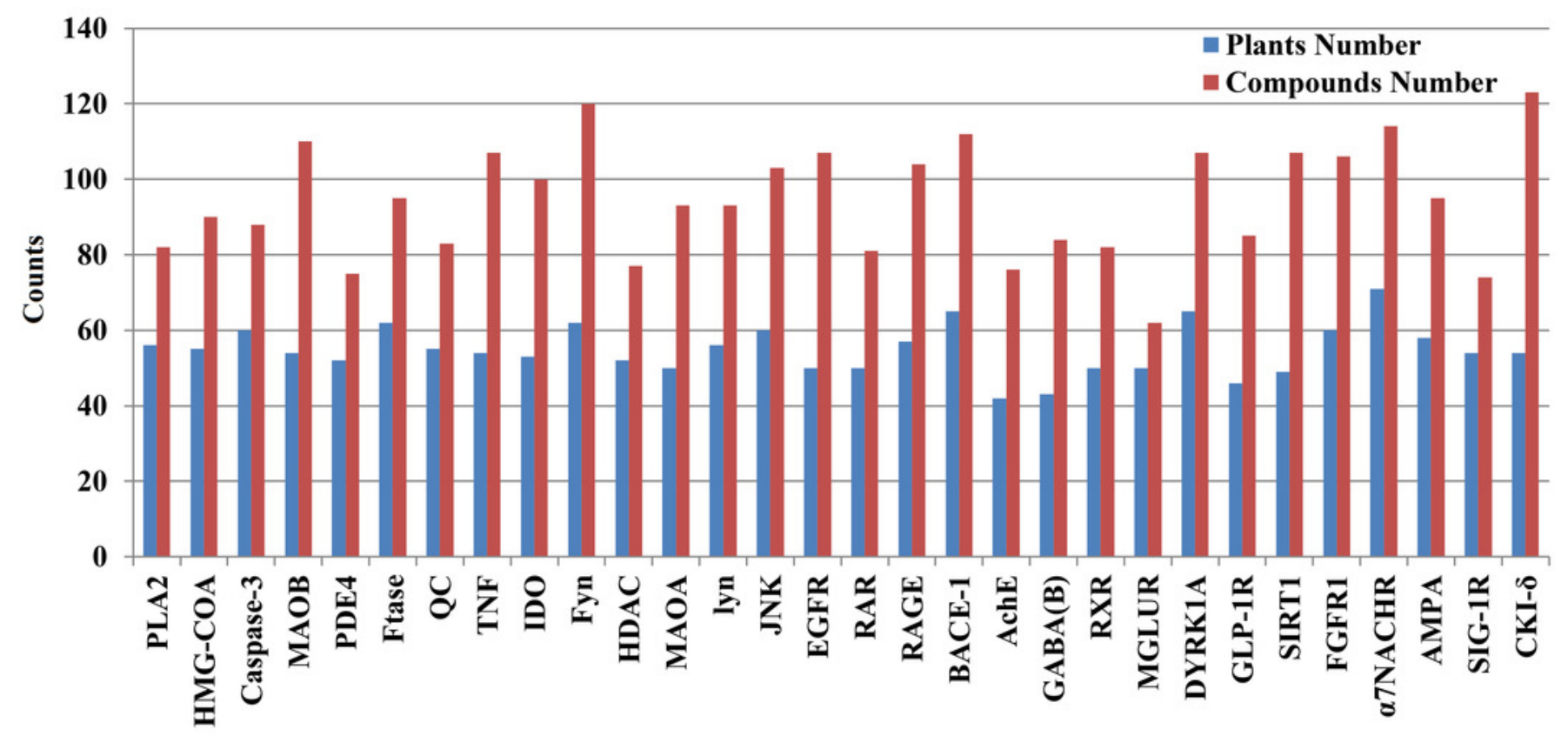




\section{Figure 4}

The network containing the target proteins and their best-associated plants

Pink boxes represent target proteins. Green boxes represent compounds.
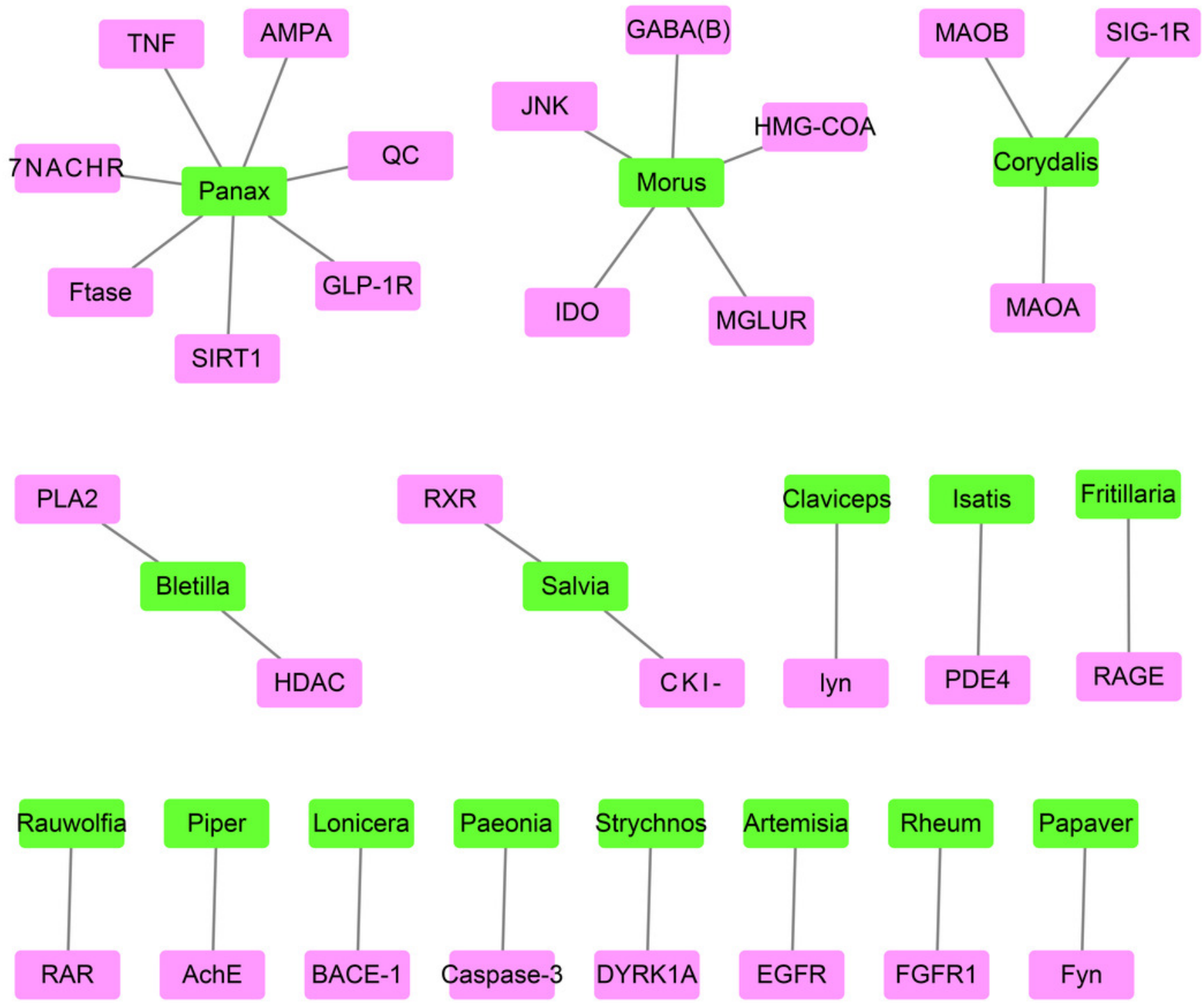
Figure 5

The network containing the anti-AD target proteins, TCM compounds and structurally identical drugs

Pink boxes represent targets. Yellow boxes represent compounds. Blue boxes represent drugs. The structures of TCM compounds are also shown.

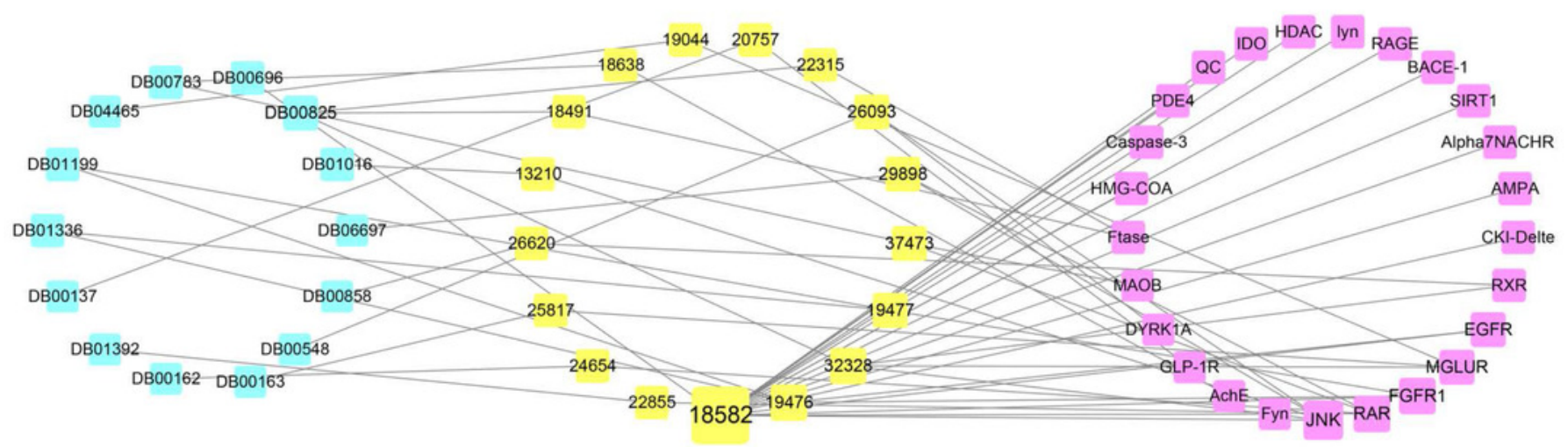

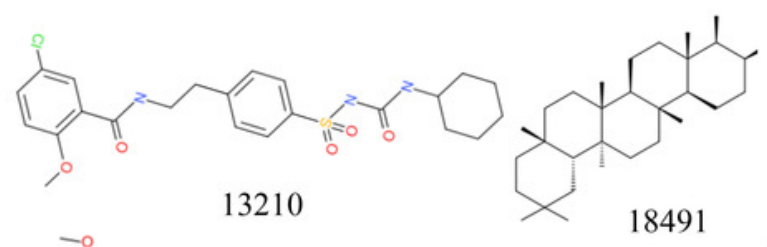
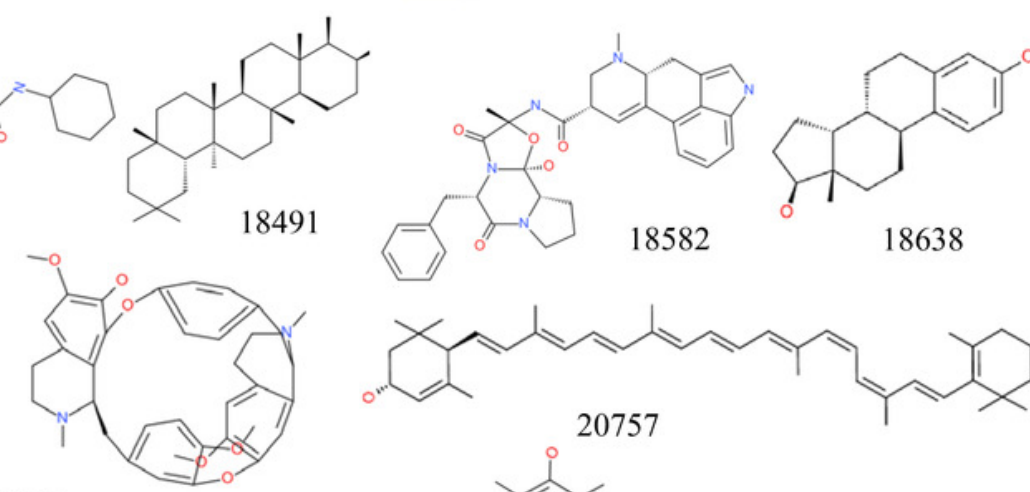

1947

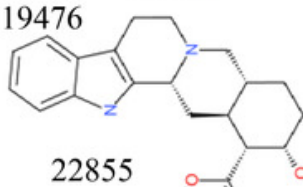<smiles>CC(C=CC1=C(C)CCCC1(C)C)=CC=CC(C)=CCO</smiles>

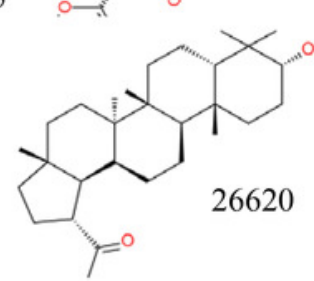

24654

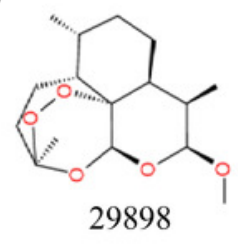

18582

18638

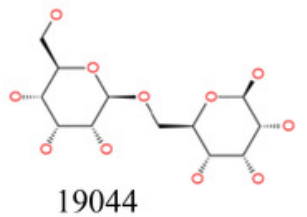

19044

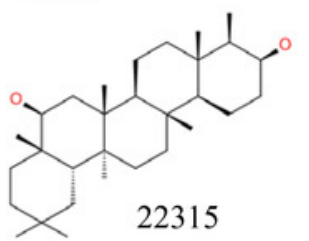

22315

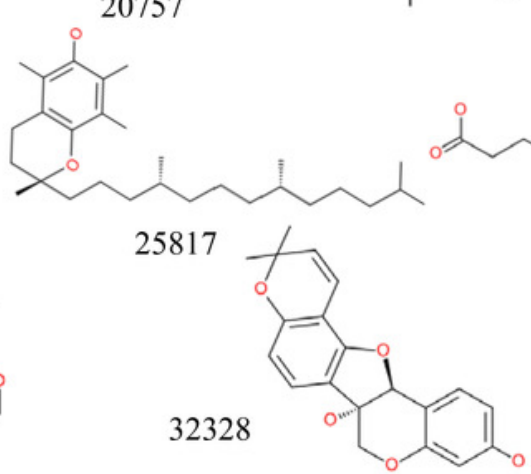

26093

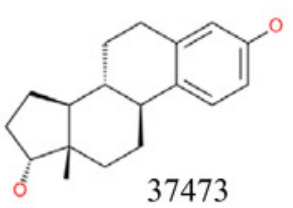




\section{Figure 6}

The 10 clusters of anti-AD TCM compounds and their primary targets

a. The Generate Maximal Common Substructure component must contain the proportion of the cluster molecules. The proportion was set to 0.5 to find the largest maximal common substructure contained in at least $50 \%$ of the cluster molecules. 


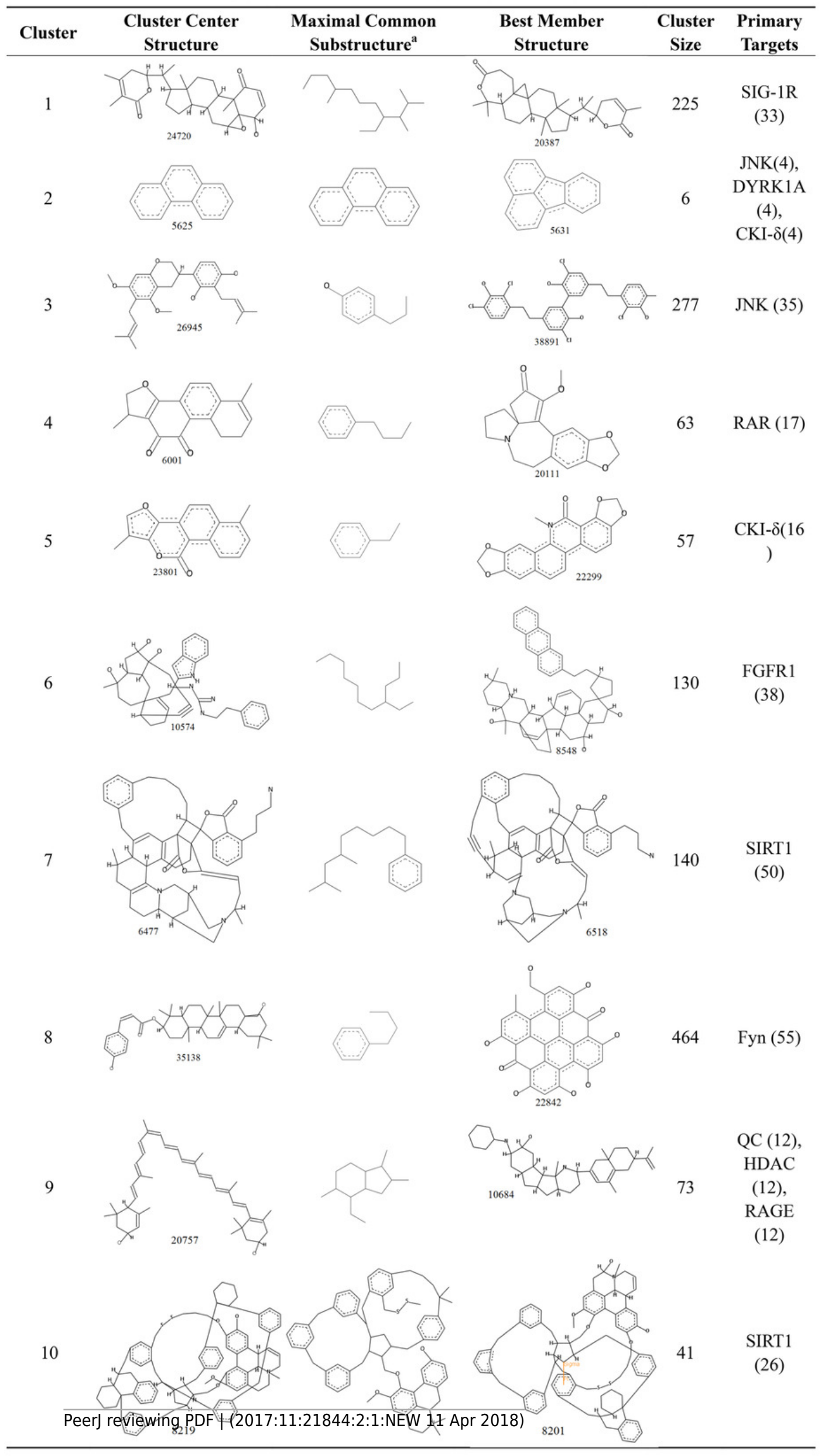


Figure 7

2D structure and corresponding plants of 11 compounds with favorable ADMET properties 


\begin{tabular}{|c|c|c|c|c|c|}
\hline $\begin{array}{c}\text { Compound } \\
\text { ID } \\
\end{array}$ & Structure & Plant & $\begin{array}{c}\text { Compound } \\
\text { ID } \\
\end{array}$ & Structure & Plant \\
\hline 5862 & & $\begin{array}{c}\text { Curcuma } \\
\text { kwangsiensis }\end{array}$ & 5863 & & $\begin{array}{c}\text { Curcuma } \\
\text { kwangsiensis }\end{array}$ \\
\hline 5868 & & $\begin{array}{c}\text { Curcuma } \\
\text { kwangsiensis }\end{array}$ & 5869 & & $\begin{array}{c}\text { Curcuma } \\
\text { kwangsiensis }\end{array}$ \\
\hline 9593 & & $\begin{array}{c}\text { Lindera } \\
\text { aggregate }\end{array}$ & 10639 & & $\begin{array}{l}\text { Taraxacum } \\
\text { mongolicum }\end{array}$ \\
\hline 16167 & & $\begin{array}{c}\text { Thermopsis } \\
\text { lanceolata R. } \\
\text { Br., } \\
\text { Laburnum } \\
\text { anagyroides, } \\
\text { Sophora } \\
\text { flavescens } \\
\text { Alt., Sophora } \\
\text { tonkinensis }\end{array}$ & 26629 & & Bletilla striata \\
\hline 28468 & & $\begin{array}{c}\text { Gerbera } \\
\text { piloselloides } \\
\text { Cass. }\end{array}$ & 28814 & & $\begin{array}{l}\text { Ophiopogon } \\
\text { japonicus (L. } \\
\text { f.) Ker-Gawl. }\end{array}$ \\
\hline 30713 & & $\begin{array}{c}\text { Glycyrrhiza } \\
\text { glabra }\end{array}$ & & & \\
\hline
\end{tabular}

